\title{
Potencialidades das mídias sociais e da gamificação na educação a distância
}

\author{
Katielen Bissolotti - Pós-Design - UFSC - kaathyie@gmail.com \\ Hamilton Garcia Nogueira - Pós-Design - UFSC - hamiltongn@gmail.com \\ Alice Theresinha Cybis Pereira - UFSC - acybis@gmail.com
}

\begin{abstract}
Resumo
A educação a distância (EaD) historicamente tem se apropriado de novas mídias e tecnologias. Com a utilização de mídias sociais e games por estudantes de diversas faixas etárias essas tecnologias demonstram potencialidades para os processos de ensino e aprendizagem, especialmente no caso da $\mathrm{EaD}$, que atualmente acontece principalmente no meio online. É abordada nesse artigo a relação entre a educação a distância, a mídia e a tecnologia, refletindo sobre as oportunidades que as mídias sociais e a gamificação podem oferecer para potencializar os processos de ensino aprendizagem e engajar os alunos através do uso desses novos recursos tecnológicos. Baseando-se nas teorias de aprendizagem sócio-construtivismo e cognição situada, são apresentadas possibilidades de utilização das mídias sociais e de processos gamificados em ambientes virtuais de aprendizagem para a EaD.
\end{abstract}

Palavras-chave: educação a distância; aprendizagem; mídias sociais; gamificação.

\section{The potential of social media and gamification in E-learning}

\begin{abstract}
E-learning has historically appropriated new media and technologies. While different age groups students use social media and games, these technologies show potential for the processes of teaching and learning, especially in the case of e-learning, which currently takes place mainly in the online environment. This article focuses on the relationship between e-learning, and media and technology, discussing the opportunities that social media and gamification can offer to enhance the learning and teaching processes, engaging students through the use of these new technological resources. Possible uses of social media and gamification processes in virtual learning environments for distance education are presented, based on the learning theories cognitivism and socio-constructivism.
\end{abstract}

Key-Words: e-learning; learning; social media; gamification.

\section{INTRODUÇÃO}

A educação a distância (EaD) pode ser considerada uma das mais democrática das modalidades de educação, pois utiliza as tecnologias de informação e comunicação para superar obstáculos na conquista do conhecimento. O Decreto 5.622, de 19.12.2005 que regulamenta o artigo 80 da LDB define educação a distância como

\footnotetext{
uma modalidade educacional na qual a mediação didático-pedagógica nos processos de ensino e aprendizagem ocorre com a utilização de meios e tecnologias de informação e comunicação, com estudantes e professores desenvolvendo atividades educativas em lugares ou tempo diversos (Decreto 5.622, art. 80 de 19.12.2005).
} 
A educação a distância vem ampliando sua colaboração na democratização do ensino e na aquisição de conhecimentos, principalmente por se constituir em um instrumento capaz de atender um grande número de pessoas simultaneamente, independentemente de sua localização geográfica.

Antes de existência das mídias digitais, muitos ensinaram e aprenderam à distância através das mídias impressas e, posteriormente, das mídias analógicas. Contudo, atualmente a educação a distância é associada, quase automaticamente, às tecnologias digitais e à conexão com a internet. De fato, ambientes virtuais de aprendizagem (AVAs), acessados por computadores, tablets e uma variedade de gadgets, têm contribuído para a ampliação e o aprimoramento da EaD.

Atualmente estudantes das mais diversas faixas etárias têm feito uso de mídias sociais $^{1}$ e muitas dessas incorporam games ou processos gamificados. Neste artigo buscou-se relacionar os serviços de mídias sociais e os processos de gamificação com a $\mathrm{EaD}$, com embasamento nas teorias de aprendizagem sócio-construtivismo e cognição situada. Dessa forma, o objetivo é discutir algumas das possibilidades de apropriação de interfaces gamificadas e de mídias sociais para os ambientes virtuais de aprendizagem, especialmente para o contexto da EaD.

\section{TEORIAS DE APRENDIZAGEM NA EAD}

A educação a distância tem se apoiado nas teorias de aprendizagem. Duas delas parecem relevantes para o atual contexto, contribuindo para embasar o uso das novas mídias e tecnologias na educação. No construtivismo, a construção do conhecimento se dá na interação ativa das pessoas com o ambiente. Dessa teoria deriva o sócioconstrutivismo, que defende a interação social como um caminho para a aprendizagem. Já a cognição situada estabelece a aprendizagem e a formação do conhecimento como atividades dinâmicas, que estão em constante reavaliação para possibilitar ao aluno novas concepções de modelos de colaboração.

\subsection{Sócio-Construtivismo}

O pensamento sócio-construtivista na educação é derivado das teorias de Jean Piaget e Lev Vygotski. Para Piaget (1970), o indivíduo constrói ativamente o conhecimento, através da interação com o meio. Em suas teorias a respeito da aquisição do conhecimento, Piaget defende que as crianças devem ter a oportunidade de descobrir e inventar as coisas por conta própria para, então, entende-las. Enquanto Vygotski (1984) propõe que, além da interação com o meio, a interação com os semelhantes também é essencial para a aprendizagem. Segundo o autor, a internalização, ou seja, a reconstrução interna de processos externos, consiste em algumas transformações:

\footnotetext{
Um processo interpessoal é transformado num processo intrapessoal. Todas as funções no desenvolvimento da criança aparecem duas vezes: primeiro, no nível social, e, depois, no nível individual; primeiro, entre pessoas (interpsicológica), e, depois, no interior da criança (intrapsicológica). Isso se aplica igualmente para a atenção voluntária, para a memória lógica e para a formação de conceitos. Todas as funções superiores originam-se das relações reais entre indivíduos humanos. (VYGOTSKY, 1984, p. 64).
}

\footnotetext{
${ }^{1}$ Disponível em: < http://www.cetic.br/publicacao/pesquisa-sobre-o-uso-das-tecnologias-de-informacaoe-comunicacao-no-brasil-tic-domicilios-e-empresas-2012/ > . Acesso em: Janeiro/2015.
} 
Dessa forma, o sócio-construtivismo se configura como uma teoria que considera as potencialidades do indivíduo, valorizando a sua interação com o ambiente e também a interação social com professores e colegas. Na ótica de Damião (2011, p. 18), ao longo da vida os seres humanos respondem a estímulos do ambiente em que estão inseridos para construir de forma ativa o próprio conhecimento, valorizando a interação social:

\begin{abstract}
Esta teoria abrange a ideia do "em processo", do conhecimento como algo não finito. Valoriza o meio físico e social em que o indivíduo se encontra e na interacção [sic] entre ambos. A aprendizagem é entendida como um processo em construção. O professor ensina, mas ao mesmo tempo incentiva o aluno a questionar o que aprende e o que existe à sua volta (DAMIÃO, 2011, p. 18).
\end{abstract}

No ensino presencial professores e alunos interagem com entre si e com os materiais didáticos por meio físico, sem maiores problematizações a respeito das provocações e estímulos para a construção do conhecimento, uma vez que eles ocorrem com naturalidade e em tempo real. Apesar das limitações impostas pela distância, a EaD utiliza ferramentas para que esses estímulos possam ocorrer. Mattar (2007, p.7) defende o potencial da EaD para o desenvolvimento de práticas pedagógicas construtivistas, visando a participação motivada, interativa e colaborativa dos alunos. Os ambientes de aprendizagem suportados pela tecnologia têm, de fato, um grande potencial para a colaboração e para essa construção de diferentes caminhos até o aprendizado. Há, porém, um fator ainda pouco explorado, inicialmente por limitações tecnológicas: a socialização. Nas práticas sócio-construtrivistas valoriza-se a ideia de que aprender é uma ação social, beneficiada pela troca de informação e experiência entre os participantes do processo.

Se na educação presencial os atos de ensinar e aprender estão automaticamente ligados ao contexto social, parece pertinente explorar essa característica na EaD, proporcionando o aprendizado através das trocas sociais, que também ajudam no fortalecimento do grupo. Conforme mencionado, outras teorias podem ser consideradas derivadas de ideias construtivistas, como a cognição situada, que, assim como o sócioconstrutivismo, também serve como base para o embasamento da $\mathrm{EaD}$, bem como o uso das mídias sociais e da gamificação na educação.

\title{
2.2 Cognição Situada
}

A cognição situada salienta a importância do contexto e da interação no processo de construção do conhecimento. Para Venâncio (2006, p. 32) todo ato cognitivo é um ato puramente experiencial, e por isso, situado, em uma junção do organismo em seu ambiente. Dessa forma, Venâncio diz que a cognição situada não representa o mundo pré-concebido, e sim, a atuação desse mundo com base em uma história da diversidade da ação desempenhada pelos indivíduos. Para compreender melhor, da cognição situada surgem as noções de aprendizagem e formação de conhecimento proveniente da interação do indivíduo com o ambiente, em um processo de influências, no qual o meio é fator expressivo nas ações e no conhecimento humano.

Lave (1988) argumenta que a aprendizagem como ocorre normalmente é uma função da atividade, do contexto e cultura em que ocorre, (isto é, situada). Segundo a autora, 
a aprendizagem não é apenas situada na prática - como se fosse algum processo independentemente reificado que só passou a ser localizado em algum lugar; a aprendizagem é uma parte integrante da prática social geradora do mundo em que se vive (LAVE; WENGER, 1991, p. 35).

Dessa forma, contrasta com muitas das atividades de aprendizagem em sala de aula, que envolvem o conhecimento abstrato e fora de contexto. A autora expõe que, "a noção de conhecimento e habilidades no processo - e como parte integral do processo de se tornar como um grande profissional sem uma comunidade prática” (LAVE, 1991, p.71). Como o iniciante, ou o recém-chegado, que se desloca da periferia da comunidade para o seu centro, o indivíduo se torna mais ativo e engajado dentro da cultura e, portanto, assume o papel de especialista ou veterano. Além disso, a aprendizagem situada é geralmente involuntária, em vez de deliberada. Estas ideias são o que Lave e Wenger (1991, p. 29) chamam de processo de "participação periférica legítima".

Enquanto para Brown et al (1989), o conhecimento, a aprendizagem e a cognição são fundamentalmente situados em atividades, contextos, culturas e situações. Os autores defendem que,

\begin{abstract}
a aprendizagem é o processo de construção de conhecimento robusta fora deste tipo de atividade incorporado. Tal abordagem de aprendizagem e do conhecimento oferece, entre outras coisas, novos insights sobre práticas pedagógicas. [...] A teoria da cognição situada ajuda a explicar "aprendizagem cognitiva". Em métodos de aprendizagem cognitiva, os professores deliberadamente implantam as circunstâncias de incorporação de conhecimentos para ajudar os alunos a construir o entendimento robusto (BROWN et al., 1989, p. 8).
\end{abstract}

O conhecimento é um produto da atividade intelectual individual e social dos alunos, portanto, os professores devem criar contextos sociais para sustentar essa produção. Wenger (2008) propõe uma comunidade de prática, como uma nova abordagem de aprender e conhecer, composta por "grupos de pessoas que compartilham uma preocupação ou uma paixão por algo que fazem e aprendem como fazê-lo melhor como eles interagem regularmente” (WENGER, 2008, p.1).

Portanto, nesta perspectiva a cognição situada poderá indicar um caminho para elaboração de soluções de aprendizagem com efeito positivo na aquisição do conhecimento, como pode ocorrer através das mídias sociais e da gamificação, ao permitir uma experiência mais abrangente e significativa, por ser incorporada emocionalmente pelo indivíduo.

\title{
3. MÍDIAS SOCIAIS
}

Além de conquistarem um espaço na rotina online de seus usuários, as mídias sociais se tornaram parte da vida dessas pessoas, não apenas em termos de interação social, mas também para fins profissionais, acadêmicos e de entretenimento. Essas mídias desempenham um papel central no conceito de Web 2.0, que emerge com características de ubiquidade e colaboratividade, a partir do ano 2000 (Santaella, 2013, p. 47). De um modo geral, qualquer tipo de mídia pode ser utilizada para diversos fins. Contudo, as características das mídias sociais, especificamente, resultantes da convergência das tecnologias que as sustentam, proporcionam algo que não era possível com as mídias tradicionais: a socialização e a comunicação em rede nas tarefas mediadas por um computador ou dispositivo móvel. 
Uma rede social é "uma metáfora para observar os padrões de conexão de um grupo social, a partir das conexões estabelecidas entre os diversos atores” (Recuero, 2009, p. 24), ou seja, sua existência não depende de tecnologias para existir, pois o termo se refere às relações humanas. Sites como o Facebook e o Twitter permitem que os usuários interajam com suas redes, sendo estas construídas pelos usuários e não prédeterminadas pelas ferramentas (Recuero, 2012, p. 20). Sobre essa relação, a autora delimita os papéis:

\begin{abstract}
Essas ferramentas pertencem à categoria cada vez mais popular dos "sites de rede social”, ou seja, ferramentas que proporcionam a publicação e construção de redes sociais. As redes sociais são as estruturas dos agrupamentos humanos, constituídas pelas interações ${ }^{2}$, que constroem os grupos sociais. Nessas ferramentas, essas redes são modificadas, transformadas pela mediação das tecnologias e, principalmente, pela apropriação delas para a conversação (RECUERO, 2012, p. 15).
\end{abstract}

Dessa forma, parece adequado que os sites de redes sociais (SRSs) sejam considerados mídias sociais, pois possibilitam trocas sociais entre os seus usuários. Resta refletir como essas mídias dialogam com a EaD, o AVA e de que forma podem contribuir para ensino e aprendizagem à distância.

O uso da internet por estudantes do ensino fundamental ao superior leva profissionais e pesquisadores a refletirem sobre o papel de tais ferramentas e as consequências dessa prática. Em uma pesquisa ${ }^{3}$ publicada pelo Centro de Estudos sobre as Tecnologias da Informação e da Comunicação (CETIC) indica-se que 70\% dos jovens brasileiros entre 9 e 16 anos possuem perfil próprio em um SRS. Entre outras atividades, como o jogar e assistir vídeos, $82 \%$ dos entrevistados dizem ter utilizado a internet para trabalho escolar no último mês. A pesquisa expõe ainda que $71 \%$ dos pais/responsáveis consideram o uso da internet seguro, mas desejam que as escolas de seus filhos sejam fonte de informação sobre segurança, além dos meios pelos quais costumam obtê-las: através da TV, rádio, jornais, revistas, família e amigos.

Enquanto as mídias sociais tornam-se cada vez mais presentes na vida dos alunos, instituições e profissionais de ensino deparam-se com o desafio de lidar com um universo mutante. Por um lado, ignorar as tecnologias parece não ser suficiente para evitar que o conhecimento compartilhado na web penetre no âmbito escolar e acadêmico, sobretudo em tempos de potentes dispositivos móveis. Por outro lado, esperar que a sociedade incorpore novas tecnologias aos sistemas de ensino sem dominá-las propriamente parece um desafio problemático. Além das questões pedagógicas, que certamente têm muito a contribuir para com o tema, embora não sejam aprofundadas nesse artigo, a vivência dos educadores também pode ser um desafio, simplesmente pelo fato de não serem usuários nativos da web. É compreensível a dificuldade em acompanhar processos de tamanha complexidade, uma vez que os usuários de SRSs costumam subverter as funcionalidades dessas ferramentas com naturalidade ao longo do tempo.

Dada a dinâmica da internet, é natural que ocorra com o passar do tempo certa defasagem em qualquer ambiente virtual, principalmente aqueles que não pertencem a grandes corporações que investem no constante aprimoramento, visando o crescimento e o lucro. Fica evidente na pesquisa do CETIC que boa parte dos jovens brasileiros é familiarizada com as mídias sociais, o que os torna potencialmente críticos a respeito de

\footnotetext{
${ }^{2}$ Na publicação a autora se refere à interação social, como sinônimo de conversação.

${ }^{3}$ Disponível em: <http://www.cetic.br/publicacao/pesquisa-sobre-o-uso-da-internet-por-criancas-eadolescentes-no-brasil/> . Acesso em: Janeiro/2015.
} 
interfaces ultrapassadas. Se os estudantes têm tanta intimidade com os SRSs, por que não aproveitar esse conhecimento para a educação? Em seu blog ${ }^{4}$ Recuero defende que os SRSs são ambientes de educação, pois considera a imitação como a primeira e mais básica forma de aprendizado. Em outro ensaio ${ }^{5}$, indo ao encontro do sócioconstrutivismo e da cognição situada, critica o pensamento da educação e aprendizagem como processos unilaterais, pois aprender é um processo social e não individual, que pode e deve ser proporcionado através da comunicação mediada por computador.

Existem alguns obstáculos a serem discutidos e superados, como os elementos distrativos e o acúmulo de informação, não apenas nas mídias sociais, mas na web de forma geral. Em sala de aula o professor frequentemente assume uma postura mediadora, estimulando a discussão entre os alunos e o compartilhamento de ideias e experiências. O mesmo pode ser feito nos ambientes virtuais na busca de uma melhor organização. Em outro contexto, VAZ (2001) discorre a respeito do excesso de informação e a necessidade da filtragem das mesmas:

\begin{abstract}
O mediador na internet aparenta-se a um corretor que aproxima os singulares em sua singularidade. [...] Se muitos podem emitir e se é fácil não atentar ao que é incessantemente produzido, como fazer para ser escutado, mesmo que cada indivíduo possa distribuir informações para todos os que estão na rede? O mediador será aquele que não apenas facilita as expressões individuais, mas também permite a cada um encontrar seu público (VAZ, 2001, p.53).
\end{abstract}

Com o devido estímulo, estudantes e professores podem aproveitar as informações, materiais e discussões que circulam em sites de redes sociais para complementar sua participação nos AVAs. Enquanto mediador, os professores e tutores que atuam na EaD podem realizar algumas das ações abaixo:

- incentivar a comunicação entre os participantes, para além das trocas de mensagens referentes ao conteúdo do curso e suas tarefas;

- proporcionar encontros por áudio e vídeo entre os participantes;

- estimular trocas sociais entre os alunos, em momentos de descontração nos encontros por vídeo conferência;

- provocar o compartilhamento de materiais externos (links, vídeos, imagens, áudios, documentos, sites, etc) entre os integrantes do grupo;

- abrir espaço para a divulgação de links dos perfis em SRSs, inclusive do próprio professor, que pode ser participativo também fora do AVA tradicional;

- identificar ambientes virtuais onde a maior parte do grupo se sinta à vontade e tirar proveito disso. Pode ser um grupo de e-mails, no Facebook, no Google Groups ou até mesmo troca de mensagens no Twitter. Com a ressalva de que, eventualmente, pode partir do grupo de alunos a criação desses espaços para a troca de mensagens, sem a presença do professor intencionalmente.

Através de iniciativas criativas de professores, diversas tecnologias estão sendo utilizadas como ferramentas de ensino. Algumas das apropriações que esse artigo sugere para os AVAs já ocorrem em sala de aula, em disciplinas de diferentes níveis de ensino, como mostram os exemplos disponíveis no blog da pesquisadora Recuero. $\mathrm{O}$

\footnotetext{
${ }^{4}$ Disponível em: <http://www.raquelrecuero.com/arquivos/2011/09/sites-de-rede-s-2.html>. Acesso em: Acesso em: Janeiro/2015.

${ }^{5}$ Disponível em: <http://www.raquelrecuero.com/arquivos/2010/07/sites-de-redes-3.html>. Acesso em: Acesso em: Janeiro/2015.
} 
desenvolvimento de uma ficção coletiva no Twitter, criação de perfis de personagens históricos ou fictícios no Facebook, ou ainda a combinação de SRSs com o Google Maps para o estudo da geografia são apenas alguns exemplos do potencial pouco explorado desses produtos hipermidiáticos que tanto têm a oferecer para a educação.

\section{GAMIFICAÇÃO}

Antes de tudo é preciso se compreender o que é um game. Karl Kapp (2012) define game como um sistema no qual os jogadores se envolvem em um desafio abstrato, definido por regras, interatividade e feedback, resultando em um resultado quantificável, muitas vezes provocando uma reação emocional. Num contexto que envolve game e aprendizagem, Kapp adiciona o conceito de reação emocional, baseada na ideia de diversão. Essa ideia de diversão é apresentada por Raph Kosten em $A$ theory of fun in Game Design.

Nos últimos anos houve uma maior inclusão dos games em diversas áreas acadêmicas, com intuito de motivar e engajar os alunos. Busca-se compreender quais as características capazes de produzir tal intensidade nas pessoas fora da "vida real”, pois nela, essas pessoas podem não se sentirem tão boas quanto são em jogos, porque quando confrontam obstáculos, tendem a sentirem-se deprimidas, frustradas e oprimidas; sentimentos que não ocorrem no ambiente do jogo.

Os games conseguem manter os jogadores concentrados em uma atividade durante horas, apenas para vencer um amigo, ultrapassar desafios e descobrir o fim da história. Na cultura atual, quase sempre o trabalho é associado com algo difícil, que requer muito esforço, entediante, uma obrigação. Mas nos jogos, o trabalho não é associado apenas a isso, pois os jogadores frequentemente passam horas formulando estratégias e depois passam muitas horas derrotando seus inimigos, coletando itens e até negociando com outros jogadores. Tarefas essas que exigem concentração, dedicação e inteligência. Os games dão trabalho, assim como o estudo, por requisitar a atividade mental dos jogadores através de seus mecanismos.

E aqui começa a gamificação. O termo gamificação (do inglês, gamification), vem sendo usado pelo marketing desde 2010, quando surge como mecanismo para solucionar problemas e alavancar grandes projetos empresariais. Segundo Zichermann (2011, p.16), gamificação é o "processo de utilizar o pensamento e as mecânicas dos games para envolver usuários e resolver problemas”. Para aplicações web, nas quais o marketing vem usando a gamificação, tal definição talvez seja aplicável. Para o uso nas práticas de aprendizagem envolvendo a educação à distância, a definição de Kapp pode ser considerada mais adequada, pois defende que a gamificação é "o uso de mecânicas, estética e pensamentos dos games para envolver pessoas, motivar a ação, promover a aprendizagem e resolver problemas" (KAPP, 2012, p.32). Outra definição para gamificação, talvez uma das mais simples e, portanto, mais versátil, é “o uso de elementos de game fora do contexto dos games” (DETERDING et al., 2011, p.10).

Para Kevin Werbach, a gamificação "é o processo de fazer atividades mais game-like” (WERBACH, 2014, p. 266). Ele explica que concebendo a gamificação como um processo, cria um melhor ajuste entre as perspectivas acadêmicas e chama a atenção para a criação de experiências game-like, ou seja, mais semelhantes aos games. E uma das vantagens é que o design persuasivo conecta-se com a gamificação. 
Burke (2014) em seu blog , afirma que é necessária uma definição atualizada para esclarecer o que é gamificação, e que a Gartner Inc. ${ }^{7}$ está redefinindo o termo como "o uso da mecânica de jogo e design de experiência para envolver digitalmente e motivar as pessoas a atingir seus objetivos".

Definindo em outras palavras, eis o seguinte exemplo. Quando uma criança volta para casa depois da escola o trajeto fica mais divertido quando brinca de não pisar nas rachaduras no chão. Isso é gamificação. É achar uma maneira divertida e engajante de fazer o que tem que ser feito. Sem a necessidade da criação de um novo jogo, com um novo cenário. O objetivo é que as pessoas desenvolvam uma motivação para que se divirtam nas tarefas que elas já têm que fazer de uma forma ou de outra. As redes sociais, aplicativos móveis e demais plataformas web são exemplos de casos em que foram utilizadas técnicas de gamificação com a finalidade de envolver os usuários: Foursquare (localização), Khan Academy (educação), LinguaLeo (idiomas), Fitocracy (fitness), Nike Plus (corrida), entre outros.

\subsection{Gamificação na Educação a Distância}

Atualmente um dos grandes desafios da educação a distância é a desmotivação que pode ocorrer entre os alunos. Muitos professores ainda utilizam o AVA como repositório de materiais didáticos, o que é um agravante. Outro problema é a quantidade de entretenimento disponível online, competindo com os livros e atividades propostas através do AVA. Alguns perfis de alunos, acostumados com mais estímulo no dia-a-dia, deparam-se com o ambiente virtual de aprendizagem e acabam ficando entediados. Buscando a solução desses problemas, descreve-se alguns mecanismos gamificados, que são úteis em ajudar na hora de engajar os alunos.

- Feedback constante: O feedback constante sobre as atividades realizadas pelo aluno é importante para dar a noção de progresso sobre o que ele está fazendo e, principalmente, para dar uma orientação sobre o próximo passo. É uma característica essencial no processo de aprendizagem e que algumas vezes não é muito bem atendida, pois quando o aluno realiza algum exercício sozinho, ele não sabe como está seu progresso ou se está no caminho certo.

- Desafios: Nos games, geralmente os desafios estão associados a um propósito, como derrotar um inimigo ou salvar o mundo. Na educação tradicional não acontece da mesma forma. Os alunos apenas veem os desafios, mas tem dificuldade em identificar um real motivo para superá-los. Por isso, é importante ligar as atividades acadêmicas com algo do "mundo real", que os alunos já conheçam, e assim, os desafios irão estimular os alunos a tomarem uma ação e superá-los. Estabelecer desafios traz ótimos resultados, pois os jogos podem diminuir o medo do fracasso, o que aumenta as chances da pessoa agir e obter sucesso.

- Competição: Não é preciso estimular a competição apenas de forma direta, elegendo apenas um vencedor a cada atividade. $\mathrm{O}$ simples fato de parabenizar as melhores notas da turma em uma prova ou numa atividade

\footnotetext{
${ }^{6}$ Disponível em: <http://blogs.gartner.com/brian_burke/2014/04/04/gartner-redefines-gamification/> Acesso em: Janeiro/2015.

${ }^{7}$ Centro de pesquisa e empresa de consultoria de tecnologia da informação. Disponível em:

$<$ http://www.gartner.com/technology/about.jsp> Acesso em: Janeiro/2015.
} 
diária, por exemplo, já promove certo nível de competição de uma maneira sadia.

- Recompensas: A recompensa é uma das características mais importantes do processo. Recompensas funcionam como espécie de feedback para que o usuário saiba que está fazendo a coisa certa, e também pode estimular os alunos para as próximas atividades. As recompensas podem vir em vários formatos, como pontos, medalhas, objetos colecionáveis ou reconhecimento. Elas podem estar pré-estabelecidas antes da realização de determinado desafio, ou podem ser concedidas com algum fator de aleatoriedade (como quando se compra um pacote de salgadinhos sem saber qual figurinha vem dentro).

As possibilidades da gamificação na educação a distância apontam para mecanismos dos games que envolvam o engajamento a determinado processo de aprendizagem, com a intenção de despertar emoções positivas, explorar aptidões pessoais ou atrelar recompensas virtuais ou físicas ao cumprimento de tarefas.

\section{CONSIDERAÇÕES}

Muitos aspectos da educação a distância não se enquadram em definições estáticas. Os atos de ensinar e aprender são constantes, mas "como" é a questão mutante. Trata-se de um processo dinâmico que não depende apenas da mídia e da tecnologia para que a evolução seja positiva. O estado, pesquisadores da área, instituições de ensino envolvidas e principalmente os professores e estudantes interagem e moldam o que é a EaD na prática. Conforme as novas mídias e tecnologias ampliam as possibilidades de interação, comunicação e socialização nos ambientes virtuais de aprendizagem, aumentam os benefícios pedagógico para a EaD.

A presença das mídias sociais e da gamificação na educação a distância está em ascensão. Estas tecnologias parecem promissoras, não para solucionar todos os obstáculos da EaD, mas como uma opção para auxiliar na solução de muitos desafios encontrados hoje nos ambientes virtuais de aprendizagem. As teorias de aprendizagem sócio-construtivismo e cognição situada parecem estar de acordo com as possibilidades de apropriação de interfaces gamificadas e de mídias sociais para os ambientes virtuais de aprendizagem.

É possível criar soluções para a educação a distância utilizando as novas mídias, buscando, através de novas experiências, influenciar a motivação e o comportamento dos alunos, alcançando o objetivo maior que é a disseminação do conhecimento. Tendo em vista o conteúdo tratado nesse artigo, reforça-se a necessidade de novos estudos sobre essas mídias e o que elas têm a oferecer para facilitar e qualificar a EaD.

\section{REFERÊNCIAS}

BRASIL. Decreto 5.622, de 19 de dezembro de 2005. Regulamenta o artigo 80 da Lei no 9.394, de 20 de dezembro de 1996, que estabelece as diretrizes e bases da educação nacional. Diário Oficial [da] República Federativa do Brasil. Brasília, DF, 20 dez. 2005. Disponível em: <http://www.planalto.gov.br/ccivil_03/_Ato2004-2006/2005/Decreto/ D5622.htm>. Acesso em: Maio/2014

BROWN, J.; Collins, A.; Duguid, P. Situated cognition and the culture of learning. Educational Researcher, 18, 32-42, 1989. 
BURKE, Brian. Gartner Redefines Gamification. Blog Gartner Inc., 2014. Disponível em: <http://blogs.gartner.com/brian_burke/2014/04/04/gartner-redefinesgamification/> . Acesso em: Janeiro/2015

DAMIÃO, Isabel Maria Esteves. Desafios para o futuro do e-Learning: uma abordagem às tecnologias educativas ferramentas de autoria, conteúdos digitais e salas virtuais. Dissertação (Mestrado), Universidade Fernando Pessoa, Porto, 2011.

DETERDING, Sebastian et al. Gamification: Toward a Definition. In: CHI Workshop Gamification: Using Game Design Elements in Non-Game Contexts. Vancouver, Canadá, 2011.

KAPP, Karl M. The gamification of learning and instruction: Game-based methods and strategies for training and education. San Francisco: Pfeiffer, 2012.

LAVE, J. Cognition in Practice: Mind, mathematics, and culture in everyday life. Cambridge, UK: Cambridge University Press, 1988.

Situating learning in communities of practice. In L. Resnick, J. Levine, and S. Teasley (Eds.), Perspectives on socially shared cognition. Washington, DC: APA, 1991.

LAVE, J.; Wenger, E. Situated learning: Legitimate peripheral participation. New York: Cambridge University Press, 1991.

MATTAR, João. Web 2.0 e redes sociais na educação a distância: cases no Brasil. Portal Educativo de las Américas, 2011. Disponível em: <https://www.educoas.org /portal/La_Educacion_Digital/laeducacion_145/studies/EyEP_mattar_ES.pdf $>$. Acesso em: Maio/2014

PIAGET, Jean. A construção do real na criança. Rio de Janeiro: Zahar, 1970.

RECUERO, Raquel. Conversação em rede: comunicação mediada pelo computador e redes sociais na internet. Porto Alegre: Sulina, 2012.

Redes sociais na internet. Porto Alegre: Sulina, 2009.

SANTAELLA, Lucia. Comunicação ubíqua: repercussões na cultura e na educação. São Paulo: Paulus, 2013.

VAZ, Paulo. Mediação e tecnologia. Porto Alegre: Revista FAMECOS, 2001.

VENÂNCIO, Ludmila Salomão; Borges, Mônica Erichsen Nassif. COGNIÇÃO

SITUADA: fundamentos e relações com a Ciência da Informação. In: Encontros Bibli: R. Eletr. Bibliotecon. Ci. Inf., Florianópolis, n. 22, 2006. 
VYGOTSKY, L. S. A formação social da mente o desenvolvimento dos processos psicológicos superiores. São Paulo: Martins Fontes, 1984.

WENGER, E. Communities of practice: a brief introduction. 2008. Disponível em: $<$ http://wenger-trayner.com/wp-content/uploads/2013/10/06-Brief-introduction-tocommunities-of-practice.pdf $>$. Acesso em: Junho/2014.

WERBACH, Kevin. (Re)Defining Gamification: A Process Approach. In: Persuasive technology: 9th International Conference, PERSUASIVE 2014, Padua, Italy, May 2123, 2014.

ZICHERMANN, Gabe; CUNNINGHAM, Christopher. Gamification by Design. Implementing Game Mechanics in Web and Mobile Apps. Canada: O’Reilly Media, 2011. 